\title{
Carotenoid Profile in Prochlorococcus sp. and Enrichment of Lutein Using Different Nitrogen Sources
}

\author{
Ayşegül Erdoğan ${ }^{1,2} \cdot$ Zeliha Demirel $^{3} \cdot$ Ahmet E. Eroğlu $^{1} \cdot$ Meltem Conk Dalay $^{3}$
}

Received: 9 January 2016/Revised and accepted: 23 April 2016/Published online: 5 May 2016

(C) Springer Science+Business Media Dordrecht 2016

\begin{abstract}
Various carotenoids of the cyanobacterium Prochlorococcus sp. are identified using chromatographic/spectroscopic techniques and quantified using HPLC-DAD. In the present study, $\beta$-apo- $8^{\prime}-$ carotenal was used as internal standard. Identification of carotenoids was carried out by comparing the retention time, absorption spectra, and mass spectra of unknown peaks with reference standards. All-trans-lutein was found to be the major carotenoid in this cyanobacterium, and, therefore, algal productivity and the potential for lutein accumulation were analyzed as a function of different nitrogen sources such as nitrate, nitrite, ammonia, and urea for cultivation. Among them, urea clearly led to the best lutein accumulation. According to the experimental evidence, lutein increased from 2.54 to $3.34 \mathrm{mg} \mathrm{g}^{-1}$ in the cyanobacteria when urea was used as the nitrogen source.
\end{abstract}

Keywords Lutein $\cdot$ Carotenoids $\cdot$ Microalgae $\cdot$ Extraction $\cdot$ Prochlorococcus sp. · HPLC-DAD

Electronic supplementary material The online version of this article (doi:10.1007/s10811-016-0861-0) contains supplementary material, which is available to authorized users.

Ayșegül Erdoğan

aysegul_erdogan@live.com; aysegul.erdogan@ege.edu.tr

1 Department of Chemistry, İzmir Institute of Technology, Urla, 35430 İzmir, Turkey

2 Present address: EGE MATAL (Ege University Application and Research Center for Testing and Analysis), Ege University, Bornova, 35100 İzmir, Turkey

3 Department of Bioengineering, Ege University, Bornova, 35100 Izmir, Turkey

\section{Introduction}

Among the photosynthetic pigments, carotenoids contain a $\mathrm{C}_{30}$ methyl-branched hydrocarbon backbone (FernándezSevilla et al. 2010). They are responsible for giving yellow, red, and orange colors in higher plants, algae, bacteria, fungi, and some animals. They are essential in light harvesting and photoprotection in all photosynthetic organisms. Moreover, carotenoids are valuable compounds used as food colorants, pharmaceuticals, and health-promoting compounds. For this reason, their worldwide demand has been growing markedly (Zhang et al. 2014). Unfortunately, there is no exact and definite extraction and saponification procedure for carotenoids as the food matrix might vary. Many organic solvents have been used and the selection of the appropriate one is not an easy task. Moreover, carotenoids are relatively stable in the matrix, whereas they are sensitive to light, heat, oxygen, and acid when they are in solution (Amorim-Carrilho et al. 2014). For these reasons, each carotenoid-containing matrix should be treated independently.

Carotenoids are lipid-soluble pigments and they may be divided into two groups: xanthophylls and carotenes. Many carotenoids have significant therapeutic properties and lutein is only one of them. Lutein is also a xanthophyllic compound, and its role in the prevention of chronic diseases and health-promoting mechanisms has been well documented. Lutein is a very effective antioxidant that also prevents and reduces the damage caused by free radicals (Richmond 1990; Le Marchand et al. 1993). It is recommended for the prevention of some types of cancer (Astorg 1997; Demmig-Adams and Adams 2002; Heber and Lu 2002), cardiovascular diseases (Dwyer et al. 2001), and retinal degeneration (Granado et al. 2003). The human body is unable to 
produce lutein; thus, this compound can only be supplied through our diet. As lutein is yellow, it efficiently absorbs the blue light part of the spectrum. Blue light can damage the retina by inducing photo-oxidative decay. Lutein acts as blue light filter in the eye, and when sufficient levels of lutein are present in the macula, blue light is absorbed and photo-oxidation is minimized (Bendich and Olson 1989; Krinsky et al. 2003). It is also referred to as the macular pigment. Intake of lutein has been strongly correlated with decreased risks of cataracts and age-related retinal degeneration (Moeller et al. 2000; Olmedilla et al. 2001; Delcourt et al. 2006; Arnal et al. 2009).

Naturally occurring lutein is produced mainly in higher plants and algae. Compared with higher plants, algae have an advantage due to the possibility of cultivation in bioreactors on a large scale and thus providing a continuous and reliable source of the product (Shi et al. 1997, 1999; Borowitzka 2010). The current commercial source of pure lutein is marigold (Tagetes erecta L.). However, the lutein content of marigold flowers is low which makes alternative lutein-rich sources interesting. Microalgae have faster growth rates and more free lutein than marigold flowers, the current source of lutein. It has been reported that the lutein production rate of microalgae is three to six times higher when compared to the lutein production rate of marigold flowers. Furthermore, in order to produce $1 \mathrm{~kg}$ of pure lutein, marigolds need more land and water, but require less nutrients $(\mathrm{N}, \mathrm{P}, \mathrm{K})$ and less energy than microalgae (Lin et al. 2015). Several microalgae are considered to be potential sources of lutein as they have high lutein $(0.5-1.2 \%$ dry weight) content (Fernández-Sevilla et al. 2010; Manke Natchigal et al. 2010).

In addition, the use of microalgae in biotechnology has gained a significant attention since they produce a great variety of metabolites that are essential to human health (Borowitzka 2013). These metabolites include proteins, vitamins, minerals, enzymes, fatty acids, xanthophylls, and carotenoids produced during normal growth phase and/or when exposed to different environmental factors (Jin et al. 2003).

Microalgae exhibit a great metabolic plasticity due to changes in response to environmental conditions, sometimes so-called stress factors. Among these, the most important factors that affect lutein content are illumination, temperature, nitrogen availability and source, salinity, the presence of oxidizing substances, and the growth rate. It should be emphasized that any of these factors can affect either lutein content or biomass productivity in opposite ways (Fernández-Sevilla et al. 2010). Therefore, it is important that the microalga should also have a high growth rate, even if exposed to stress conditions in order to induce the accumulation of lutein in order to achieve high lutein productivity.

The interest in lutein from microalgae is still relatively new. Several microalgae have been proposed as potentially useful to produce lutein, such as Muriellopsis sp. (Del Campo et al. 2001; Blanco et al. 2007), Chlorella zofingiensis (=Chromochloris zofingiensis) (Del Campo et al. 2001), Chlorella protothecoides (=Auxenochlorella protothecoides) (Wei et al. 2008), or 'Scenedesmus almeriensis' (Sánchez et al. 2008). Most of these studies have shown how the culture conditions and biomass productivity were optimized to increase the amount of lutein. Apart from this, it should be noted that solvent extraction conditions may also be a consideration as each microalgal species have different morphologies. There is no exact procedure for the determination of carotenoids or a specific type of carotenoid in microalgae. For this reason, new studies must be directed towards its accurate identification and quantification.

The aims of this study were to investigate the carotenoid composition of a novel cyanobacterium, Prochlorococcus sp., by using chromatographic/spectroscopic techniques and enhance its lutein content by altering the source of nitrogen in culture media.

\section{Materials and methods}

\section{Chemicals}

All carotenoid standards were obtained from CaroteNature and trans- $\beta$-apo- 8 '-carotenal and pyrogallol were purchased from Sigma-Aldrich. All the solvents used were LC grade and obtained from Sigma-Aldrich.

\section{Instrumentation}

An Agilent 1200 Series HPLC-DAD system was used for the determination of carotenoids. Prior to use, all HPLCgrade mobile phases were degassed using an (Elmasonic $\mathrm{S} 80 \mathrm{H})$ ultrasonic bath.

The reversed phase column selected for use was a YMC carotenoid $\mathrm{C}_{30}, 250 \mathrm{~mm} \times 4.6 \mathrm{~mm}, 5 \mu \mathrm{m}$ (Waters, USA). The

Table 1 Gradient program optimized for the analysis of carotenoids by ${ }^{\mathrm{a}} \mathrm{HPLC}$ DAD

\begin{tabular}{llll}
\hline \multicolumn{3}{l}{ Solvents containing 0.1} & $\%$ TEA \\
\hline Time (min) & MeOH & MTBE & $\mathrm{H}_{2} \mathrm{O}$ \\
\hline 0 & 70 & 25 & 5 \\
5 & 60 & 35 & 5 \\
10 & 45 & 55 & 0 \\
15 & 25 & 75 & 0 \\
\hline
\end{tabular}

${ }^{\mathrm{a}}$ Detection was done at $446 \mathrm{~nm}$ on $\mathrm{C}_{30}$ column with a flow rate of $1.0 \mathrm{~mL} \mathrm{~min}^{-1}$ 
mobile phase consisted of methanol, methyl-tert-butyl ether, and water containing $0.1 \%$ TEA and $0.01 \%$ pyrogallol with a gradient program at a flow rate of $1.0 \mathrm{~mL} \mathrm{~min}{ }^{-1}$. The injection volume was $20.0 \mu \mathrm{L}$, and detection was by diode array detector with quantitation at $446 \mathrm{~nm}$. The column temperature was set at $25.0^{\circ} \mathrm{C}$. The spectrum from 300 to $600 \mathrm{~nm}$ was recorded and stored for tentative identification of other carotenoids. The details of the gradient program are presented in Table 1.

Extraction of carotenoids was performed by using ultrasonic bath. The solvents were removed by rotary evaporator (Heidolph Hei-VAP Advantage).

\section{Cultivation and preparation of Prochlorococcus sp.}

Prochlorococcus sp. was obtained from the Ege University Microalgae Culture Collection, Ege-MACC (coded with EGEMACC73 http://www.egemacc.com/cultures.php) with National Center for Biotechnology Information (NCBI) accession numbers JQ726703.1, JQ726702.1, and JQ726701.1. It was isolated from Burdur Lake, Turkey. It was cultivated in Bold's basal medium (BBM) (Andersen et al. 2005) (Table S1). The cells in 2.0-L bottles were illuminated with continuous light $\left(27 \mu \mathrm{mol}\right.$ photons $\mathrm{m}^{-2} \mathrm{~s}^{-1}$; cool white fluorescent lamps, Philips, $18 \mathrm{~W} / 54$ ) at $25.0^{\circ} \mathrm{C}$. Air was supplied to the culture at a flow rate of $1 \mathrm{~L} \mathrm{~min}^{-1}(1.25 \mathrm{vvm})$. Four-dayold culture (in exponential cell growth phase) was used as inoculum at $10 \%$ volume for all experiments. All glassware and the medium were autoclaved at $121.0{ }^{\circ} \mathrm{C}$ for $20.0 \mathrm{~min}$ prior to use. When this medium was used, the specific growth rate was 0.203 day $^{-1}$ calculated according to Becker (1993) (Eq. 1) using the data obtained by the absorbance values taken at $450 \mathrm{~nm}$.

$\mu=\frac{\ln x_{2}-\ln x_{1}}{\Delta t}$

where $\mu=$ specific growth rate, $x_{2}=$ cell concentration at time $t_{2}, x_{1}=$ cell concentration at time $t_{1}$, and $\Delta t=t_{2}-t_{1}$.
The Prochlorococcus sp. cultures were filtered by Whatman No. 1 filter paper and washed with deionized water to remove the growing medium. The harvested cells were stored at $-20.0^{\circ} \mathrm{C}$ and lyophilized prior to extraction of carotenoids.

\section{Identification of Prochlorococcus sp.}

For the identification of the cyanobacteria, optical image was obtained by using a trinocular light microscope (Olympus $\mathrm{CH} 40$ ) and SEM image was provided using Philips XL-30S FEG (Fig. 1). The elemental composition of Prochlorococcus sp. was determined with an LECO-932 elemental analyzer, and according to the results, it mainly consists of $47.06 \% \mathrm{C}$, $6.92 \% \mathrm{~N}, 7.05 \% \mathrm{H}$, and $0.64 \% \mathrm{~S}$ by mass.

\section{Preparation of standard carotenoid solutions}

As carotenoids are light sensitive, standard solutions were prepared under yellow light (Philips lamp TLD 36 W/16 yellow, light transmission at 500-750 nm) at room temperature within the shortest possible time. All stock carotenoid standards were accurately weighed and dissolved in $10.0 \mathrm{~mL}$ dichloromethane, whereas $10.0 \mathrm{mg}$ of trans- $\beta$-apo- $8^{\prime}$-carotenal (internal standard) was dissolved in $10.0 \mathrm{~mL}$ chloroform (stabilized with $1 \%$ ethanol) to produce stock solutions which were then diluted to obtain appropriate intermediate standard solutions of $100.0 \mathrm{mg} \mathrm{L}^{-1}$. Calibration standards were prepared containing a constant concentration of the internal standard and a variable concentration of carotenoid for the construction of calibration curves. All standard and sample solutions were kept in amber-colored volumetric flasks wrapped with aluminum foil.

Different concentrations $\left(0.010-5.0 \mathrm{mg} \mathrm{L}^{-1}\right)$ of available carotenoid standards were injected into the HPLC, and the linear regression equations for each calibration curve were acquired by plotting the quantity of standard compound injected against their ratio of analyte peak area to the internal standard peak area. Measurement of the magnitude of analytical background
Fig. 1 a Optical microscope image $(\times 40)$ and $\mathbf{b}$ SEM image $(\times 50,000)$ for Prochlorococcus sp.
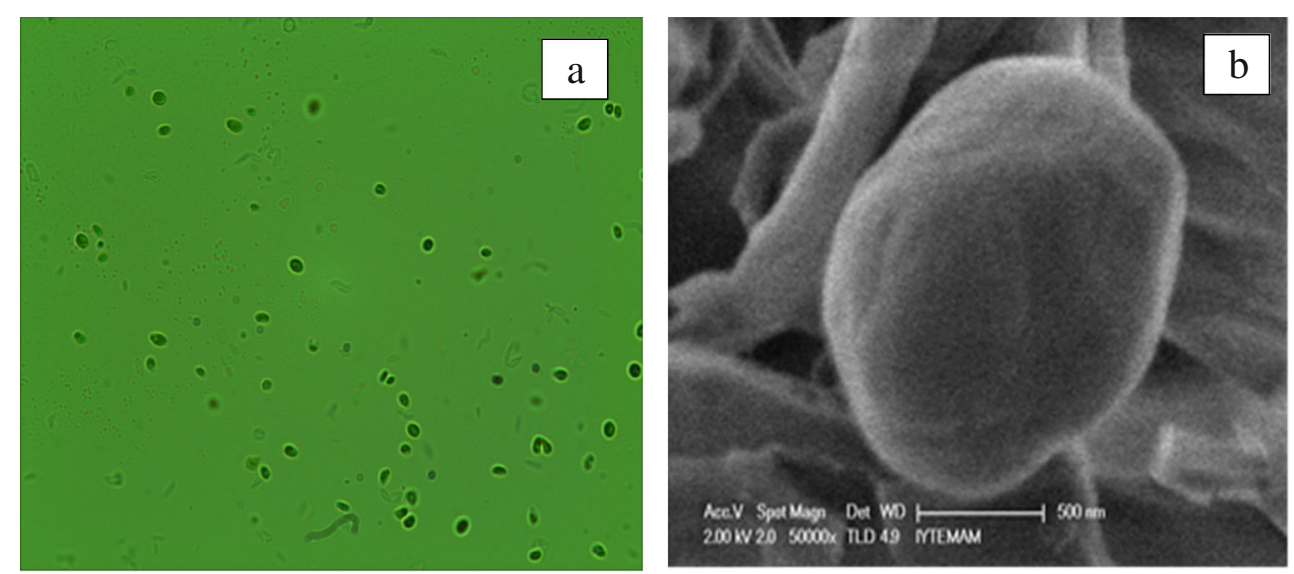


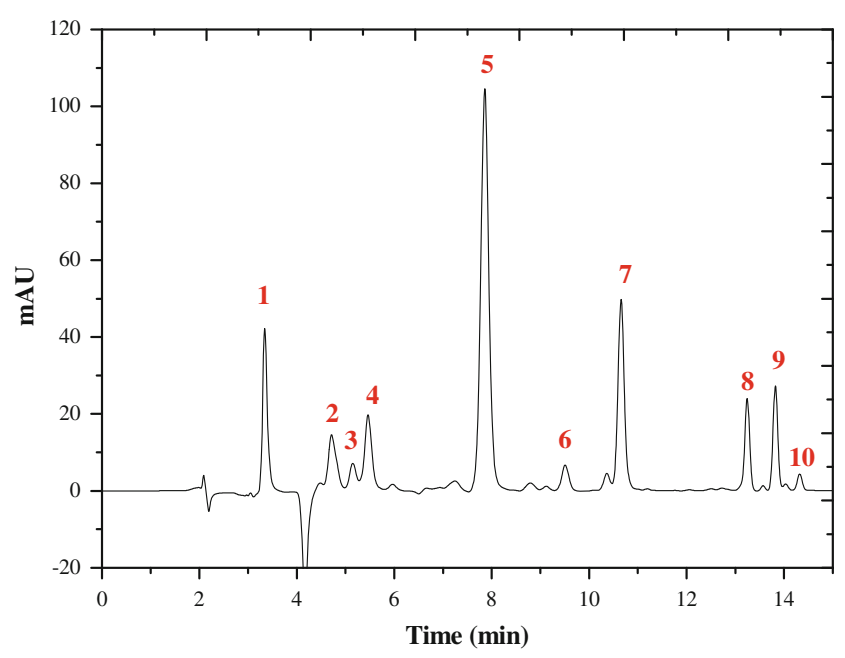

Fig. 2 HPLC chromatogram for Prochlorococcus sp. obtained at $446 \mathrm{~nm}$ : (1) degraded chlorophyll, (2) all-trans-neoxanthin, (3) all-trans-violaxanthin, (4) 9-cis-violaxanthin, (5) all-trans-lutein, (6) 9- or 9'-cis-lutein, (7) trans- $\beta$-apo-8'carotenal, (8) all-trans- $\beta, \varepsilon$-carotene, (9) all-trans- $\beta, \beta$-carotene, (10) 9-cis- $\beta, \beta$ carotene

response was performed by analyzing an appropriate number of blank samples and calculating the standard deviation of these responses. Ten repeats of blank sample were tested. Using the standard deviation of the blank sample, the detection and quantification limits were set. The mean of the ten repeats, plus three times the standard deviation, is the detection limit, while ten times the standard deviation is the quantification limit.

\section{Extraction and saponification of carotenoids from Prochlorococcus sp.}

The extraction and saponification of carotenoids from Prochlorococcus sp. were performed according to the procedure reported in our previous study in which the method validation was also performed (Erdoğan et al. 2015).
In brief, $0.25 \mathrm{~g}$ of dry microalgal biomass was treated with $10.0 \mathrm{~mL}$ of tetrahydrofuran:dichloromethane $(1: 1 \mathrm{v} / \mathrm{v})$ solution for the extraction of carotenoids using an ultrasonic bath (37 kHz) to disrupt the algal cells. The saponification procedure was performed (10\% methanolic potassium hydroxide) for $2.0 \mathrm{~h}$ in order to remove the unwanted lipids and the chlorophylls. The solvent of the carotenoid solution was removed by rotary evaporation. Finally, it was dissolved in the mobile phase prior to HPLC analysis.

The same methodology was followed for the identification and quantification of carotenoids in Prochlorococcus sp.

\section{Effect of different nitrogen sources on lutein content}

In this study, different nitrogen sources were provided such as nitrite, ammonium, and urea as some literature studies have implied that nitrogen content increases with increased lutein availability and growth rate (Shi et al. 2000). FernándezSevilla et al. (2010) have pointed out that nitrogen availability and source are one of the most important factors that affect the lutein content in microalgae. Apart from nitrate, nitrite, ammonium, and urea have been selected as the different nitrogen sources in order to change the lutein productivity of both microalgae used in this study. An equivalent nitrogen concentration was used in the culture media for the comparison of nitrogen sources with the nitrate.

\section{Results and discussion}

\section{Identification of and determination of carotenoids in Prochlorococcus sp.}

The gradient system developed by Erdoğan et al. (2015) was applied for the separation of carotenoids in the selected

Table 2 UV-visible absorption spectra for tentative identification of carotenoids in Prochlorococcus sp.

\begin{tabular}{|c|c|c|c|c|c|c|c|c|c|c|c|}
\hline \multirow{2}{*}{$\frac{\text { Peak no }}{2}$} & \multirow{2}{*}{$\begin{array}{l}\text { Compound } \\
\text { All-trans-neoxanthin }\end{array}$} & \multicolumn{3}{|c|}{$\lambda(\text { reported })^{\mathrm{a}}$} & \multicolumn{3}{|c|}{$\lambda$ (observed) } & \multicolumn{3}{|c|}{$\lambda$ (standards) } & \multirow{2}{*}{$\frac{\% \mathrm{III} / \mathrm{II}^{\mathrm{c}}}{85.1}$} \\
\hline & & 418 & 442 & 471 & 418 & 440 & 471 & 418 & 440 & 471 & \\
\hline 3 & All-trans-violaxanthin & 419 & 440 & 470 & 417 & 440 & 470 & 418 & 440 & 470 & 94.0 \\
\hline 4 & 9-cis-Violaxanthin & 414 & 436 & 464 & 418 & 440 & 470 & & & & 96.2 \\
\hline 5 & All-trans-lutein & 422 & 445 & 474 & 423 & 446 & 474 & 424 & 446 & 474 & 64.3 \\
\hline 6 & 9- or 9'-cis-lutein & 420 & 442 & 470 & 418 & 440 & 470 & & & & 67.9 \\
\hline 7 & Internal standard ${ }^{\mathrm{b}}$ & & 458 & & & 456 & & & 456 & & \\
\hline 8 & All-trans- $\beta, \varepsilon$-carotene & 423 & 444 & 473 & 423 & 446 & 474 & 423 & 446 & 474 & 59.2 \\
\hline 9 & All-trans- $\beta, \beta$-carotene & 428 & 450 & 478 & & 452 & 478 & & 452 & 478 & 22.4 \\
\hline 10 & 9-cis- $\beta, \beta-$ Carotene & 422 & 448 & 474 & 423 & 446 & 474 & 423 & 446 & 474 & 30.9 \\
\hline
\end{tabular}

${ }^{\text {a }}$ Britton et al. 2004

b trans- $\beta$-apo-8'-Carotenal

${ }^{\mathrm{c}}$ Spectral fine structure: ratio of the longest wavelength absorption peak (designated as III) and that of the middle absorption peak (designated as II) 
Table 3 LC-APCI-MS (positive mode) data of carotenoids in Prochlorococcus sp.

\begin{tabular}{|c|c|c|c|c|}
\hline Peak No & Carotenoid & $m / z$ (observed) & $m / z$ (standards) & $m / z$ (reported) ${ }^{\mathrm{a}}$ \\
\hline 2 & All-trans-neoxanthin & $\begin{array}{l}601.5[M+\mathrm{H}]^{+}, 583.5\left[M+\mathrm{H}-\mathrm{H}_{2} \mathrm{O}\right]^{+} \\
\quad 565.4\left[M+\mathrm{H}-2 \mathrm{H}_{2} \mathrm{O}\right]^{+}\end{array}$ & $601.5,583.5,565.4$ & $\begin{array}{l}601[M+\mathrm{H}]^{+}, 583\left[M+\mathrm{H}-\mathrm{H}_{2} \mathrm{O}\right]^{+}, 565 \\
\quad\left[M+\mathrm{H}-2 \mathrm{H}_{2} \mathrm{O}\right]^{+}\end{array}$ \\
\hline 3 & All-trans-violaxanthin & $\begin{array}{l}601.5[M+\mathrm{H}]^{+}, 583.5\left[M+\mathrm{H}-\mathrm{H}_{2} \mathrm{O}\right]^{+} \\
\quad 509.4[M+\mathrm{H}-92]^{+}\end{array}$ & $601.5,583.5,509.4$ & $\begin{array}{l}601[M+\mathrm{H}]^{+}, 583\left[M+\mathrm{H}-\mathrm{H}_{2} \mathrm{O}\right]^{+}, 509 \\
\quad[M+\mathrm{H}-92]^{+}\end{array}$ \\
\hline 4 & 9-cis-Violaxanthin & $601.5[M+\mathrm{H}]^{+}$ & & $601[M+\mathrm{H}]^{+}$ \\
\hline 5 & All-trans-lutein & $569.5[M+\mathrm{H}]^{+}, 551.5\left[M+\mathrm{H}-\mathrm{H}_{2} \mathrm{O}\right]^{+}$ & $569.5,551.5$ & $569[M+\mathrm{H}]^{+}, 551\left[M+\mathrm{H}_{-} \mathrm{H}_{2} \mathrm{O}\right]^{+}$ \\
\hline 6 & 9- or 9'-cis-lutein & $569.5[M+\mathrm{H}]^{+}$ & & $569[M+\mathrm{H}]^{+}$ \\
\hline 8 & All-trans- $\beta, \varepsilon$-carotene & $537.4[M+\mathrm{H}]^{+}, 519.4\left[M+\mathrm{H}-\mathrm{H}_{2} \mathrm{O}\right]^{+}$ & $537.4,519.4$ & $537[M+\mathrm{H}]^{+}, 519\left[M+\mathrm{H}_{-} \mathrm{H}_{2} \mathrm{O}\right]^{+}$ \\
\hline 9 & All-trans- $\beta, \beta$-carotene & $537.4[M+\mathrm{H}]^{+}, 519.4\left[M+\mathrm{H}-\mathrm{H}_{2} \mathrm{O}\right]^{+}$ & $537.4,519.4$ & $538[M+\mathrm{H}]^{+}, 519\left[M+\mathrm{H}-\mathrm{H}_{2} \mathrm{O}\right]^{+}$ \\
\hline 10 & 9-cis- $\beta, \beta$-Carotene & $537.4[M+\mathrm{H}]^{+}, 519.4\left[M+\mathrm{H}-\mathrm{H}_{2} \mathrm{O}\right]^{+}$ & $537.4,519.4$ & $539[M+\mathrm{H}]^{+}, 519\left[M+\mathrm{H}-\mathrm{H}_{2} \mathrm{O}\right]^{+}$ \\
\hline
\end{tabular}

${ }^{\mathrm{a}}$ Britton et al. 2004

cyanobacteria. Internal standard calibration method was used for the determination of carotenoids. This LC-DAD method is fast, specific, and precise for the determination of carotenoids. An HPLC chromatogram for Prochlorococcus sp. is shown in Fig. 2. All the carotenoids were separated within $15 \mathrm{~min}$. The first peak in the chromatogram is considered to be a degradation product of chlorophyll that might stem from the saponification process. For this reason, the negative peak observed in the fourth minute could also be due to a chlorophyll degradation product.

For the identification of carotenoids, absorbance values and mass spectrometric data were combined. Figure S1 shows absorbance spectra for available carotenoid standards and carotenoids extracted from Prochlorococcus sp. UV-visible absorption spectra for tentative identification of carotenoids are presented in Table 2. In addition, spectral fine structural values (\% II/II) obtained from this study agree well with the values in the literature (Britton et al. 2004). LC-APCI-MS (positive mode) data of carotenoids in Prochlorococcus sp. are also summarized in Table 3.

Finally, Table 4 presents the validation parameters regarding the proposed LC method for Prochlorococcus sp.

\section{Improving the lutein content using different nitrogen sources}

A number of different nitrogen sources, such as ammonia, nitrate, nitrite and urea, can be used as nitrogen source for growing microalgae (Becker 2004). Among these, urea $\left(\mathrm{CO}\left(\mathrm{NH}_{2}\right)_{2}\right)$ is a low molecular weight, polar, and relatively lipid-insoluble organic compound which can be considered as a combined source of nitrogen and carbon. In the literature, several examples can be found where urea has been shown to be an effective combined source of $\mathrm{N}$ and $\mathrm{C}$ for the production of Arthrospira platensis, Neochloris oleoabundans, and Chlorella sp. under different cultivation modes (Becker 2004; Rangel-Yagui et al. 2004; Sánchez-Luna et al. 2004; Soletto et al. 2005; Li et al. 2008; Hsieh and $\mathrm{Wu} 2009$ ).

This part of the study aimed at assessing the effect of different nitrogen sources on biomass productivity and lutein accumulation of Prochlorococcus sp. Table 5 shows the growth rates and lutein accumulation of cultures grown on different $\mathrm{N}$ sources. For an equivalent nitrogen

Table 4 Summarized validation parameters with proposed LC method (gradient elution with 70:25:5 methanol:methyl tert-butyl ether:water at the wavelength of interest, flow rate $1.0 \mathrm{~mL} \mathrm{~min}^{-1}$ ) for Prochlorococcus sp.

\begin{tabular}{|c|c|c|c|c|c|c|c|}
\hline Compound & $\operatorname{LOD}\left(\mathrm{mg} \mathrm{L}^{-1}\right)$ & $\mathrm{LOQ}\left(\mathrm{mg} \mathrm{L}^{-1}\right)$ & $r^{2}$ & Peak purity $\%$ & Capacity factor $\left(k^{\prime}\right)$ & Selectivity factor $(\alpha)$ & Content ( $\left.\mathrm{mg} \mathrm{g}^{-1}\right)$ \\
\hline All-trans-neoxanthin & 0.011 & 0.035 & 0.9997 & 99.3 & 1.43 & 1.87 & 0.45 \\
\hline All-trans-violaxanthin & 0.014 & 0.045 & 0.9998 & 98.9 & 1.60 & 1.12 & 1.39 \\
\hline 9-cis-Violaxanthin & \multicolumn{3}{|c|}{ No available standard } & 97.5 & 2.10 & 1.31 & ND \\
\hline All-trans-lutein & 0.0032 & 0.011 & 0.9998 & 99.5 & 3.11 & 1.49 & 2.54 \\
\hline 9- or 9'-cis-lutein & \multicolumn{3}{|c|}{ No available standard } & 97.5 & 3.91 & 1.27 & ND \\
\hline All-trans- $\beta, \varepsilon$-carotene & 0.016 & 0.054 & 0.9997 & 98.6 & 5.67 & 1.27 & 0.24 \\
\hline All-trans- $\beta$-carotene & 0.012 & 0.042 & 0.9995 & 99.1 & 5.99 & 1.06 & 0.30 \\
\hline 9-cis- $\beta, \beta$-Carotene & 0.015 & 0.051 & 0.9995 & 97.6 & 6.25 & 1.04 & 0.13 \\
\hline
\end{tabular}

RSD values are $<2 \%$

$N D$ not detected 
Table 5 Growth rates and lutein accumulation of Prochlorococcus sp. grown in different N sources

\begin{tabular}{|c|c|c|c|}
\hline Nitrogen sources & Log phase (day) & $\mu_{\max }\left(\right.$ day $\left.^{-1}\right)$ & ${ }^{\mathrm{a}}$ All-trans-lutein accumulated $\left(\mathrm{mg} \mathrm{g}^{-1}\right)$ \\
\hline $\mathrm{NaNO}_{3}$ & $4-8$ & 0.419 & 2.54 \\
\hline $\mathrm{NaNO}_{2}$ & $4-8$ & 0.376 & 1.82 \\
\hline $\mathrm{NH}_{4} \mathrm{Cl}$ & $3-10$ & 0.262 & 0.42 \\
\hline $\mathrm{CH}_{4} \mathrm{~N}_{2} \mathrm{O}$ & $4-8$ & 0.232 & 3.34 \\
\hline
\end{tabular}

RSD values are $<2 \%$

${ }^{\text {a }}$ Experiments were performed three times

concentration, urea gave a higher yield for lutein. Some authors (Goldman 1977; Stengel and Soeder 1975) have reported that ammonium was an excellent nitrogen source for marine as well as freshwater algae. On the other hand, it has not been used as widely as nitrate as a nitrogen source for most algae such as Chlorella protothecoides (Shi et al. 2000) and Dunaliella salina (Borowitzka and Borowitzka 1988) which might be due to its inconvenience for sterilization, and the lethal effect on cells due the severe drop in $\mathrm{pH}$ after ammonium has been consumed. Urea as a nitrogen source was found to be superior in several respects to the commonly used nitrogen source, nitrate.

On the other hand, growth rates in cultures grown on urea were lower than the growth rates when other nitrogen sources are used. This might be due to the fact that urea is an organic source while the rest are inorganic sources of nitrogen. Probably, the accumulation of lutein due to utilization of organic source may not be the same due to metabolic pathways when inorganic sources are used. In addition, this organic compound can be considered as a combined source of nitrogen and carbon. The reason why urea gave higher yields for an equivalent nitrogen concentration might be due to the fact that it is usually hydrolyzed into ammonia and bicarbonate and therefore leads smaller $\mathrm{pH}$ fluctuations in the medium during the algal growth (Perez-Garcia et al. 2011).

\section{Conclusion}

In recent years, there has been particular emphasis on obtaining more accurate data on the types and concentrations of carotenoids in foods for various health and nutrition activities. On the other hand, significant attention has recently been drawn to the use of microalgae since they produce carotenes and xanthophylls in rich amounts during their normal growth or when exposed to stress conditions. For this reason, carotenoid production has become one of the most successful branches of biotechnology of microalgae. According to the experimental data obtained via chromatographic and spectroscopic analyses, the identification and quantification of carotenoids in Prochlorococcus sp. have been explored. It has been shown that lutein is the most abundant carotenoid in the selected microalga. In addition, availability of different nitrogen sources has significantly affected its lutein content. Urea as nitrogen source is advantageous for the accumulation of lutein as it is a cheap $\mathrm{N}$ source which could then be an interesting alternative to the traditional nitrate-based media for the microalgae. In conclusion, our work provides necessary information about the carotenoid profiles and the enhanced productivity for lutein from Prochlorococcus sp. using different types of nitrogen sources.

Acknowledgments The authors would like to acknowledge the Scientific and Technological Research Council of Turkey for the support of this work through the project TBAG 110T099 and also the Center of Material's Research at İzmir Institute of Technology for the facilities (SEM and Elemental Analyzer).

\section{References}

Amorim-Carrilho K, Cepeda A, Fente C, Regal P (2014) Review of methods for analysis of carotenoids. Trends Anal Chem 56:49-73

Andersen RA, Berges JA, Harrisson PJ, Watanabe MM (2005) Recipes for freshwater and seawater media. In: Anderson RA (ed) Algal culturing techniques. Elsevier Academic Press, Amsterdam, pp $429-538$

Arnal E, Miranda M, Almansa I, Muriach M, Barcia JM, Romero FJ, Diaz-Llopis M, Bosch-Morell F (2009) Lutein prevents cataract development and progression in diabetic rats. Graefes Arch Clin Exp Ophthalmol 247:115-120

Astorg P (1997) Food carotenoids and cancer prevention: an overview of current research. Trends Food Sci Technol 8:406-413

Becker EW (1993) Microalgae: biotechnology and microbiology,. Cambridge University Press

Becker W (2004) Microalgae in human and animal nutrition. In: Richmond A (ed) Microalgal culture: biotechnology and applied phycology. Blackwell Science, Oxford, pp 312-351

Bendich A, Olson JA (1989) Biological actions of carotenoids. FASEB J 3:1927-1932

Blanco AM, Moreno J, Del Campo JA, Rivas J, Guerrero MG (2007) Outdoor cultivation of lutein-rich cells of Muriellopsis sp. in open ponds. Appl Microbiol Biotechnol 73:1259-1266

Borowitzka MA (2010) Carotenoid production using microorganisms. In: Cohen Z, Ratledge C (eds) Single cell oils. Microbial and algal oils. AOCS Press, Urbana, pp 225-240 
Borowitzka MA (2013) High-value products from microalgae - their development and commercialisation. J Appl Phycol 25:743-756

Borowitzka MA, Borowitzka LJ (1988) Limits to growth and carotenogenesis in laboratory and large-scale outdoor cultures of Dunaliella salina. In: Stadler T, Mollion J, Verdus MC, Karamanos Y, Morvan H, Christiaen D (eds) Algal biotechnology. Elsevier Applied Science, Barking, pp 371-381

Britton G, Liaaen-Jensen S, Pfander H, Mercadante AZ, Egeland ES (2004) Carotenoids - Handbook. Birkhäuser Verlag, Basel, CH

Del Campo JA, Rodriguez H, Moreno J, Vargas M, Rivas J, Guerrero MG (2001) Lutein production by Muriellopsis sp. in an outdoor tubular photobioreactor. J Biotechnol 85:289-295

Delcourt C, Carriere I, Delage M, Barberger-Gateau P, Schalch W (2006) Plasma lutein and zeaxanthin and other carotenoids as modifiable risk factors for age-related maculopathy and cataract: the POLA Study. Invest Ophthalmol Vis Sci 47:2329-2335

Demmig-Adams B, Adams WW (2002) Antioxidants in photosynthesis and human nutrition. Science 298:2149-2153

Dwyer JH, Navab M, Dwyer KM, Hassan K, Sun P, Shircore A, HamaLevy S, Hough G, Wang X, Drake T (2001) Oxygenated carotenoid lutein and progression of early atherosclerosis the Los Angeles atherosclerosis study. Circulation 103:2922-2927

Erdoğan A, Çağır A, Dalay MC, Eroğlu AE (2015) Composition of carotenoids in Scenedesmus protuberans: application of chromatographic and spectroscopic methods. Food Anal Methods 8:19701978

Fernández-Sevilla J, Acién Fernández F, Molina Grima E (2010) Biotechnological production of lutein and its applications. Appl Microbiol Biotechnol 86:27-40

Goldman JC (1977) Biomass production in mass cultures of marine phytoplankton at varying temperatures. J Exp Mar Biol Ecol 27:161169

Granado F, Olmedilla B, Blanco I (2003) Nutritional and clinical relevance of lutein in human health. Br J Nutr 90:487-502

Heber D, Lu QY (2002) Overview of mechanisms of action of lycopene. Exp Biol Med 227:920-923

Hsieh C-H, Wu W-T (2009) Cultivation of microalgae for oil production with a cultivation strategy of urea limitation. Bioresour Technol 100: 3921-3926

Jin E, Polle JE, Lee H, Hyun S, Chang M (2003) Xanthophylls in microalgae: from biosynthesis to biotechnological mass production and application. J Microbiol Biotechnol 13:165-174

Krinsky NI, Landrum JT, Bone RA (2003) Biologic mechanisms of the protective role of lutein and zeaxanthin in the eye. Annu Rev Nutr 23:171-201

Le Marchand L, Hankin JH, Kolonel LN, Beecher GR, Wilkens LR, Zhao LP (1993) Intake of specific carotenoids and lung cancer risk. Cancer Epidemiol Biomarkers Prev 2:183-187

Li Y, Horsman M, Wang B, Wu N, Lan CQ (2008) Effects of nitrogen sources on cell growth and lipid accumulation of green alga Neochloris oleoabundans. Appl Microbiol Biotechnol 81:629-636
Lin J-H, Lee D-J, Chang J-S (2015) Lutein production from biomass: marigold flowers versus microalgae. Bioresour Technol 184:421428

Manke Natchigal A, Oliveira Stringheta A, Corrêa Bertoldi M, Stringheta P (2010) Quantification and characterization of lutein from Tagetes (Tagetes patula L.) and Calendula (Calendula officinalis L.) flowers. In: XXVIII International Horticultural Congress on Science and Horticulture for People (IHC2010): International Symposium on 939, 2010. pp 309-314

Moeller SM, Jacques PF, Blumberg JB (2000) The potential role of dietary xanthophylls in cataract and age-related macular degeneration. $\mathrm{J}$ Am Coll Nutr 19(supl 5):522S-527S

Olmedilla B, Granado F, Blanco I, Vaquero M, Cajigal C (2001) Lutein in patients with cataracts and age-related macular degeneration: a longterm supplementation study. J Sci Food Agric 81:904-909

Perez-Garcia O, Escalante FM, de-Bashan LE, Bashan Y (2011) Heterotrophic cultures of microalgae: metabolism and potential products. Water Res 45:11-36

Rangel-Yagui CO, Danesi EDG, de Carvalho JCM, Sato S (2004) Chlorophyll production from Spirulina platensis: cultivation with urea addition by fed-batch process. Bioresour Technol 92:133-141

Richmond A (1990) Large scale microalgal culture and applications. Prog Clin Biol Res 7:269-330

Sánchez J, Fernández J, Acién F, Rueda A, Pérez-Parra J, Molina E (2008) Influence of culture conditions on the productivity and lutein content of the new strain Scenedesmus almeriensis. Process Biochem 43:398-405

Sánchez-Luna LD, Converti A, Tonini GC, Sato S, de Carvalho J (2004) Continuous and pulse feedings of urea as a nitrogen source in fedbatch cultivation of Spirulina platensis. Aquac Eng 31:237-245

Shi XM, Chen F, Yuan JP, Chen H (1997) Heterotrophic production of lutein by selected Chlorella strains. J Appl Phycol 9:445-450

Shi XM, Liu HJ, Zhang XW, Chen F (1999) Production of biomass and lutein by Chlorella protothecoides at various glucose concentrations in heterotrophic cultures. Process Biochem 34:341-347

Shi X-M, Zhang X-W, Chen F (2000) Heterotrophic production of biomass and lutein by Chlorella protothecoides on various nitrogen sources. Enzyme Microb Technol 27:312-318

Soletto D, Binaghi L, Lodi A, Carvalho J, Converti A (2005) Batch and fed-batch cultivations of Spirulina platensis using ammonium sulphate and urea as nitrogen sources. Aquaculture 243:217-224

Stengel E, Soeder C (1975) Control of photosynthetic production in aquatic ecosystems. In: Cooper JP (ed) Photosynthesis and productivity in different environments. Cambridge University Press, Cambridge, pp 645-660

Wei D, Chen F, Chen G, Zhang X, Liu L, Zhang H (2008) Enhanced production of lutein in heterotrophic Chlorella protothecoides by oxidative stress. Sc1 Chına Ser C 51(12):1088-1093

Zhang J, Sun Z, Sun P, Chen T, Chen F (2014) Microalgal carotenoids: beneficial effects and potential in human health. Food Funct 5:413425 